\title{
Quantifying the effects of spirulina supplementation on plasma lipid and glucose concentrations, body weight, and blood pressure
}

This article was published in the following Dove Press journal: Diabetes, Metabolic Syndrome and Obesity:Targets and Therapy

\author{
Haohai Huang' \\ Dan Liao ${ }^{2}$ \\ Rong $\mathrm{Pu}^{3}$ \\ Yejia $\mathrm{Cui}^{3}$
}

'Department of Clinical Pharmacy, Dongguan Third People's Hospital, Affiliated Dongguan Shilong People's Hospital of Southern Medical University, Dongguan, Guangdong, China; ${ }^{2}$ Department of Gynaecology, Dongguan Third People's Hospital, Affiliated Dongguan Shilong People's Hospital of Southern Medical University, Dongguan, Guangdong, China; ${ }^{3}$ Department of Clinical Laboratory, Dongguan Third People's Hospital, Affiliated Dongguan Shilong People's Hospital of Southern Medical University, Dongguan, Guangdong, China

\footnotetext{
Correspondence: Haohai Huang Department of Clinical Pharmacy, Dongguan Third People's Hospital, Affiliated Dongguan Shilong People's Hospital of Southern Medical University, No. I, Huangzhou Xianglong Road of Shilong Town, Dongguan, Guangdong 523326, China

Tel +8607698136883 I

Fax +86076981368802

Email haohaihuang@hotmail.com
}

Purpose: Spirulina is generally used as a nutraceutical food supplement due to its nutrient profile, lack of toxicity, and therapeutic effects. Clinical trials have investigated the influence of spirulina on metabolic-related risk factors but have yielded conflicting results in humans. Here, we summarize the evidence of the effects of spirulina on serum lipid profile, glucose management, BP, and body weight by conducting a meta-analysis.

Materials and methods: Relevant studies were retrieved by systematic search of MEDLINE, EMBASE, Scopus databases, and reference lists of relevant original studies from inception to July 2018. Data were extracted following a standardized protocol. Two investigators independently extracted study characteristics, outcomes measures, and appraised methodological quality. Effect sizes were performed using a random-effects model, with weighted mean differences (WMDs) and $95 \%$ CIs between the means for the spirulina intervention and control arms. Subgroup analyses were conducted to explore the possible influences of study characteristics. Publication bias and sensitivity analysis were also performed.

Results: A total of 1,868 records were identified of which 12 trials with 14 arms were eligible. The amount of spirulina ranged from 1 to $19 \mathrm{~g} / \mathrm{d}$, and intervention durations ranged from 2 to 48 weeks. Overall, data synthesis showed that spirulina supplements significantly lowered total cholesterol (WMD $=-36.60 \mathrm{mg} / \mathrm{dL} ; 95 \% \mathrm{CI}:-51.87$ to $-21.33 ; P=0.0001$ ), low-density lipoprotein cholesterol $(\mathrm{WMD}=-33.16 \mathrm{mg} / \mathrm{dL} ; 95 \% \mathrm{CI}:-50.52$ to $-15.75 ; P=0.0002)$, triglycerides $(\mathrm{WMD}=-39.20 \mathrm{mg} / \mathrm{dL} ; 95 \% \mathrm{CI}:-52.71$ to $-25.69 ; P=0.0001)$, very-low-density lipoprotein cholesterol (WMD $=-8.02 \mathrm{mg} / \mathrm{dL} ; 95 \% \mathrm{CI}:-8.77$ to $-7.26 ; P=0.0001$ ), fasting blood glucose (WMD $=-5.01 \mathrm{mg} / \mathrm{dL} ; 95 \% \mathrm{CI}:-9.78$ to $-0.24 ; P=0.04$ ), and DBP (WMD $=-7.17 \mathrm{mmHg}$; $95 \% \mathrm{CI}:-8.57$ to $-5.78 ; P=0.001)$. These findings remained stable in the sensitivity analysis, and no obvious publication bias was detected.

Conclusion: Our findings provide substantial evidence that spirulina supplementation has favorable effect on select cardiovascular and metabolic biomarkers in humans, including lipid, glucose, and DBP management.

Keywords: blood pressure, body weight, blood glucose, CVD, lipid, spirulina

\section{Introduction}

CVD is the major cause of morbidity, mortality, and disability worldwide; with the global aging of populations, the prevalence of CVD is increasing rapidly. ${ }^{1}$ According to the World Health Organization reports, >17.3 million people die of CVD every year, and the number of CVD-related deaths is projected to rise to $>23.6$ million by the year 2030. ${ }^{1}$ Accumulating epidemiological evidence revealed that dyslipidemias and hypertension are the key factors for the pathogenesis and development of CVD. ${ }^{2,3}$ Compared 
with healthy subjects, those patients with hyperlipidemia and elevated BP are at increased risk of heart attack, strokes, and ischemic heart disease. ${ }^{4-6}$ Based on the guidelines of American Heart Association/American College of Cardiology (AHA/ ACC) and the European Society of Cardiology (ESC), the primary target for CVD prevention and treatment is to decrease the potential CVD risk factors by reducing LDL-C, BP, body weight, and glucose to recommended levels. ${ }^{7}$ In recent decades, the potential cardiovascular protective properties of natural products have been reported, with evidence to confirm that dietary natural products or functional foods supplementation were generally applied to improve lipid management, insulin resistance, BP control, markers of inflammation and antioxidant status, and CVD-related complications. ${ }^{8-12}$

Spirulina (Arthrospira platensis), a species of filamentous cyanobacteria, is generally used as a nutraceutical food supplement. Spirulina is rich in vitamins, minerals, protein, carotenoids, phycocyanins, essential fatty acids, and other bioactive molecules such as phenolic acids, tocopherols, and glinolenic acid. ${ }^{13,14}$ Spirulina platensis and Spirulina maxima have been broadly studied in the field of medicine and food industry due to its nutrient profile, lack of toxicity, and therapeutic effects. Accumulating evidence has shown that spirulina exerts health promoting functions, including antioxidant, anti-inflammatory, antitumor, antiviral, antibacterial activities, as well as positive effects against hyperlipidemia, obesity, and diabetes. ${ }^{15-18}$ In clinical practice, several studies are focusing on the potential effects of spirulina on the prevention and treatment of CVD due to its high antioxidant activity. ${ }^{19-23}$ However, results are inconsistent and no meta-analysis has specifically pooled nor summarized the precise effect of spirulina consumption on cardiovascular risk factors. We therefore undertook a comprehensive meta-analysis to investigate the effects and safety of spirulina supplementation on multiple markers of cardiovascular health in humans. The present study provides an insight into the potential clinical applications of spirulina in CVD and may also highlight some suggestions for future research.

\section{Materials and methods Protocol and guidelines}

This pooled analysis was based on a protocol that was prepared according to recommendations described in the Cochrane Handbook and report based on the PRISMA guidelines. $^{24}$

\section{Trial and patient inclusion criteria}

Only trials were eligible for inclusion in this study satisfied the following criteria: 1) studies using spirulina as only intervention and studies in which spirulina was combined with other interventions were included when the control group received the same treatment; 2 ) the doses of spirulina intervention were reported in the trial; 3) studies with a parallel or crossover design that compared spirulina with placebo or no treatment control; 4) studies were human clinical trials; 5) studies should be providing sufficient information on baseline and post-treatment outcome markers in both spirulina and control groups; 6) the primary metabolic risk factors were TC, LDL-C, HDL-C, TG, vLDL-C, FBG, HbA1c, SBP, DBP, body weight, and BMI.

\section{Data sources and literature search}

We performed a systematic literature search of several databases, including MEDLINE (http://www.ncbi.nlm.nih.gov/ pubmed), EMBASE (http://www.embase.com), and Scopus databases (https://www.scopus.com) from inception to July 1, 2018. Specifically, we used the following Medical Subject Headings (MeSH) and corresponding key words as search terms: ("spirulina" OR "spirulina*" OR "spirulina platensis" OR "spirulina maxima” OR "spirulina fusiformis" OR "Arthrospira"). The search was limited to English-language publications and clinical trials that conducted in human subjects. To identify any other potentially missing paper, manual searches of reference lists in relevant papers, specialist journals, and conference proceedings were also performed. Trials identified from literature searches were listed, and the trials included were selected using the criteria described above. All authors participated in the selection of trials for inclusion.

\section{Assessment of study quality and data extraction}

Two independent reviewers completed data extraction and quality assessment. The qualities of included studies were assessed using the Cochrane risk-of-bias tool. ${ }^{25}$ We obtained information on randomization sequence generation, allocation concealment, blinding of participants and study personnel, blinding of outcome assessors, incomplete outcome data, selective reporting, and other biases. The risk of bias in each study was judged to be "low," "high," or "unclear." The data were extracted using a predesigned data collection check form, and disagreements were resolved through discussion. Trial characteristics recorded included author identification, year of publication, study population, sample size, details of the study design, length of follow-up, participants' mean age, spirulina dose and formulation used, types of control, and outcomes of interest. In each trial, the means and SDs of the primary outcomes at the baseline and endpoint both 
in intervention and control groups were extracted. If the SDs were not provided directly, we calculated them from standard error mean (SEM) or $95 \%$ CI with the equations listed in the Cochrane handbook.

\section{Statistical analysis}

For continuous outcomes, we calculated the effect sizes as WMD and 95\% CI between the spirulina intervention and control arms. The degree of statistical heterogeneity among studies was determined using the $I^{2}$ statistic, with a value of $<25 \%, 26 \%-50 \%$, and $>50 \%$ considered as low, moderate, and high level of heterogeneity, respectively. ${ }^{26}$ All analyses were based on the random-effects model. In order to evaluate the robustness of our findings, sensitivity analyses were performed by removing one study each time and pooling the remaining ones (the "leave one out" approach). Potential moderating factors were evaluated by subgroup analysis including types of controls used, spirulina dose, and intervention duration. The subgroup analyses were performed only for the effect of spirulina products on lipid profiles because of small numbers of studies for other outcomes. The presence of publication bias was assessed visually and quantitatively using Egger's weighted regression statistics. ${ }^{27}$ All statistical analyses were performed using STATA software version 12.0 (StataCorp LP, College Station, TX, USA). Reported $P$-values are two tailed, and $P<0.05$ was considered significant for all analyses, except where otherwise specified.

\section{Results}

\section{Search results and trial flow}

From the electronic searches, 1,868 potential literature citations were retrieved. On review of references from relevant identified reviews, an additional 12 studies potentially meeting our inclusion criteria were identified. Of these, 56 articles were selected for detailed evaluation. After full-text assessment according to the inclusion and exclusion criteria, 44 of these studies were excluded. Overall, a total of 12 studies (equivalent to 14 treatment arms) with 807 participants were finally considered to be selected for the current metaanalysis. ${ }^{19-23,28-34}$ Study selection and identification process are depicted in Figure 1.

\section{Characteristics and quality of the included studies}

The details of the study characteristics of the sample, interventions, outcome assessment, and results are provided in Table 1. These included studies were published between 1996 and 2017 and were conducted in five different countries, including India,
Korea, USA, Cameroon, and Poland. The number of participants ranged from 20 to 169 . The mean age of participants in each trial ranged from 7.28 to 65.9 years. A range of doses from 1 to $19 \mathrm{~g} / \mathrm{d}$ of spirulina was administered in the included trials. The duration of the spirulina intervention varied from 2 to 24 weeks, with nine studies having treatment durations $\geq 12$ weeks and the remaining three having treatment durations $<12$ weeks. All trials were designed as parallel-group studies. Among the included studies, five trials used the placebo as the control, six trials used no intervention as the control, and one study used soybean as the control. Selected studies were performed in subjects who suffered from type 2 diabetes mellitus, HIV-infected, hypertension, ischemic heart disease, and hyperlipidemic nephrotic syndrome. The systematic assessment of risk-of-bias summary is provided in Figure S1. Overall, five trials were considered as a low risk of bias, six as a high risk of bias, and one as unclear.

\section{Effect of spirulina supplementation on plasma lipid and glucose concentrations, body weight, and BP}

For the change of lipid profiles, as shown in Figure 2, the pooled result showed that spirulina supplements significantly lower the TC (12 treatment arms; WMD $=-36.60 \mathrm{mg} / \mathrm{dL}$; 95\% CI: -51.87 to $\left.-21.33 ; P=0.0001 ; \mathrm{I}^{2}=93 \%\right)$, LDL-C (11 treatment arms; WMD $=-33.16 \mathrm{mg} / \mathrm{dL} ; 95 \% \mathrm{CI}:-50.52$ to $\left.-15.75 ; P=0.0002 ; \mathrm{I}^{2}=96 \%\right)$, TG (12 treatment arms; WMD $=-39.20 \mathrm{mg} / \mathrm{dL} ; 95 \% \mathrm{CI}:-52.71$ to $-25.69 ; P=0.0001$; $\mathrm{I}^{2}=73 \%$ ), and vLDL-C (five treatment arms; WMD $=-8.02$ $\mathrm{mg} / \mathrm{dL} ; 95 \% \mathrm{CI}:-8.77$ to $-7.26 ; P=0.0001 ; \mathrm{I}^{2}=0 \%$ ). However, spirulina intervention may not significantly change the levels of HDL-C (11 treatment arms; WMD $=5.81 \mathrm{mg} / \mathrm{dL} ; 95 \% \mathrm{CI}$ : 0.10 to $11.51 ; P=0.05 ; \mathrm{I}^{2}=94 \%$ ). Other markers of CVD risk are listed in Table 2 . For the change of BP, consumption with spirulina showed a significant decrease in DBP (four treatment arms; $\mathrm{WMD}=-7.17 \mathrm{mmHg} ; 95 \% \mathrm{CI}:-8.57$ to -5.78 ; $P=0.0001 ; \mathrm{I}^{2}=0 \%$ ) but not SBP (four treatment arms; WMD $=-3.49 \mathrm{mmHg} ; 95 \% \mathrm{CI}:-7.19$ to $0.21 ; P=0.06 ; \mathrm{I}^{2}=50 \%$ ). Finally, spirulina consumption significantly lowered FBG (eight treatment arms; WMD $=-5.01 \mathrm{mg} / \mathrm{dL} ; 95 \% \mathrm{CI}:-9.78$ to $\left.-0.24 ; P=0.04 ; \mathrm{I}^{2}=77 \%\right)$. No significant changes were found for body weight (seven treatment arms; WMD $=-1.51$ $\mathrm{kg} ; 95 \% \mathrm{CI}$ : -3.39 to $0.36 ; P=0.11 ; \mathrm{I}^{2}=0 \%$ ), BMI (five treatment arms; WMD $=-0.44\left(\mathrm{~kg} / \mathrm{m}^{2}\right) ; 95 \% \mathrm{CI}:-1.87$ to 0.99 ; $P=0.54 ; \mathrm{I}^{2}=71 \%$ ), and $\mathrm{HbA} 1 \mathrm{c}$ (three treatment arms; WMD $=-0.34 ; 95 \% \mathrm{CI}:-0.79$ to $0.11 ; P=0.14 ; \mathrm{I}^{2}=78 \%$ ) following spirulina supplementation. The high levels of statistical heterogeneity were found in most of the analysis. 


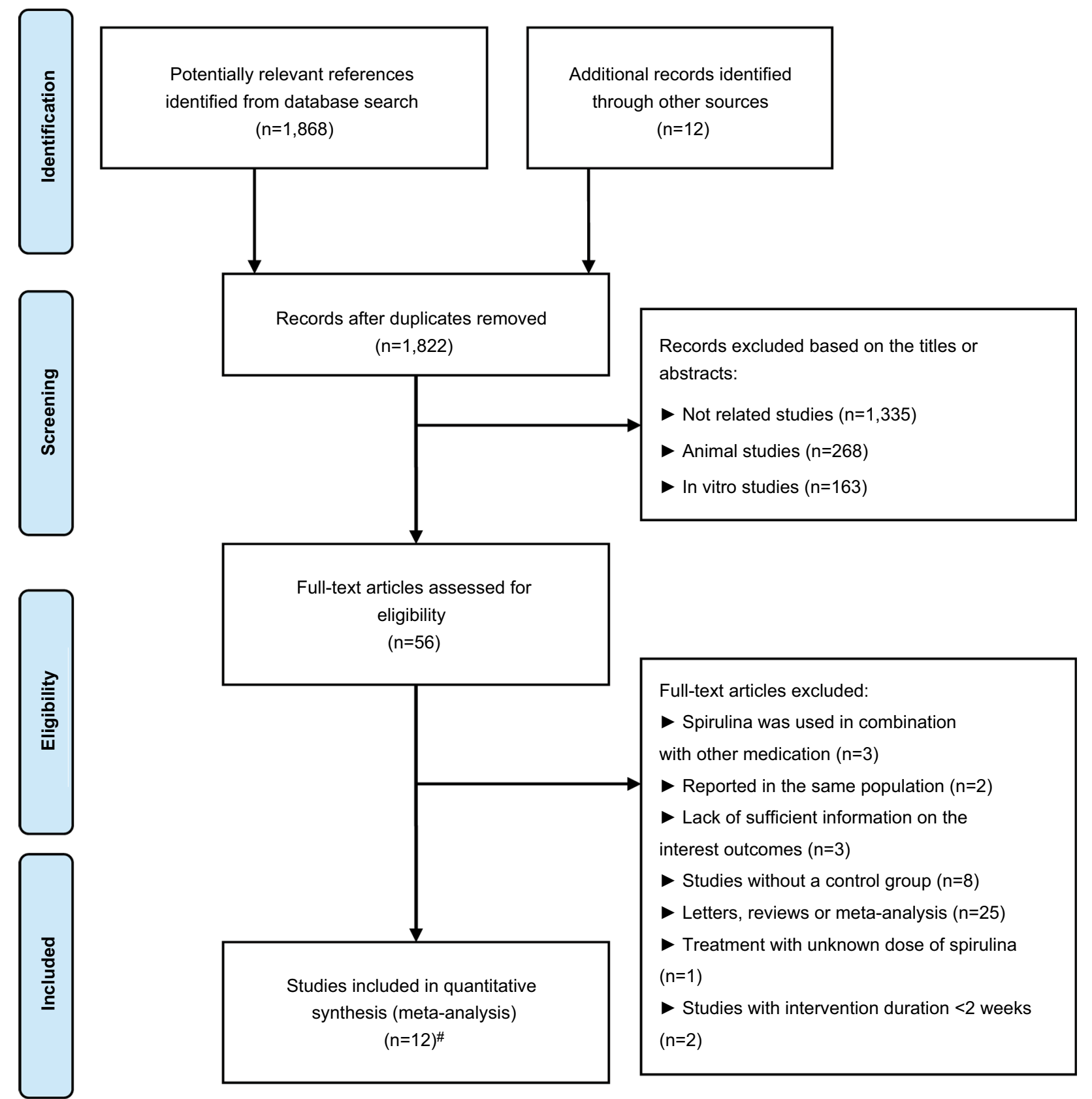

Figure I Flowchart of database searches and articles included in the present meta-analysis.

Notes: ${ }^{\#}$ The work conducted by Ramamoorthy et $\mathrm{al}^{21}$ and Park et $\mathrm{a}^{20}$ were separated into two treatment arms, respectively.

\section{Subgroup analysis}

Subgroup analyses were conducted to evaluate the overall effects of spirulina on plasma lipid concentrations in prespecified subgroups, including types of controls used (no intervention or placebo), spirulina dose $(<2$ or $\geq 2 \mathrm{~g} / \mathrm{d})$, and intervention duration ( $<12$ or $\geq 12$ weeks). Subgroup analysis results based on the spirulina dose demonstrate that spirulina consumption significantly decreased the level of TC (WMD $=-35.41 \mathrm{mg} / \mathrm{dL} ; 95 \% \mathrm{CI}:-51.43$ to -19.39 ; $P=0.0001), \mathrm{LDL}-\mathrm{C}(\mathrm{WMD}=-37.62 \mathrm{mg} / \mathrm{dL} ; 95 \% \mathrm{CI}:-63.23$ to $-12.00 ; P=0.004)$, and TG (WMD $=-41.65 \mathrm{mg} / \mathrm{dL} ; 95 \%$ CI: -63.18 to $-20.12 ; P=0.0001)$ in subjects with spirulina supplementation $\geq 2 \mathrm{~g} / \mathrm{d}$. The trials stratified by duration of intervention showed that subjects with spirulina intervention $\geq 12$ weeks significantly reduced the concentrations of TC $(\mathrm{WMD}=-38.88 \mathrm{mg} / \mathrm{dL} ; 95 \% \mathrm{CI}:-56.05$ to -21.72 ; 


\begin{tabular}{|c|c|c|c|c|c|c|c|c|c|}
\hline 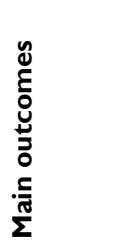 & 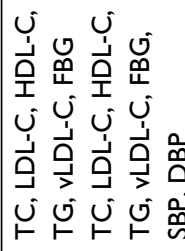 & & 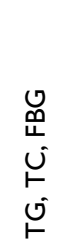 & 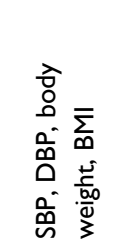 & 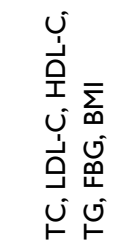 & 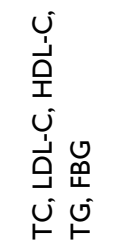 & 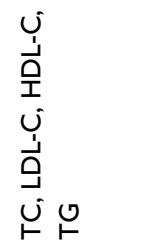 & 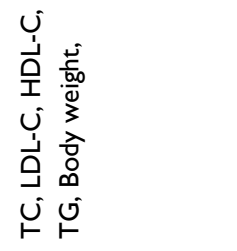 & 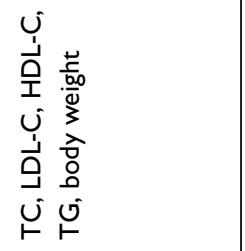 \\
\hline 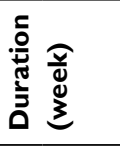 & $\simeq \quad \simeq$ & $N$ & $\infty$ & $\simeq$ & $\stackrel{ \pm}{\sim}$ & $\infty$ & $\underline{0}$ & $\simeq$ & $\simeq$ \\
\hline 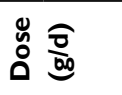 & $-\infty$ & $\stackrel{m}{i}$ & $\underline{a}$ & $n$ & 으 & n & $\infty$ & $n$ & $\sigma$ \\
\hline 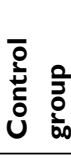 & : & 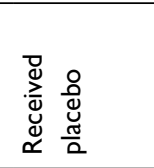 & \multicolumn{2}{|c|}{ 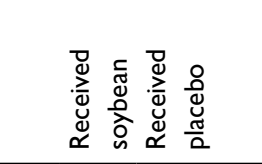 } & 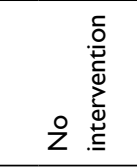 & 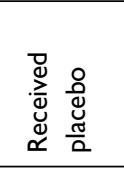 & 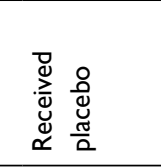 & 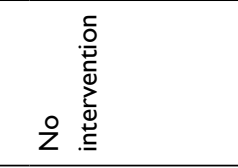 & 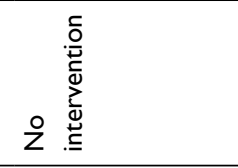 \\
\hline 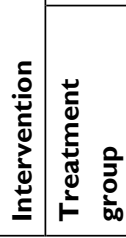 & 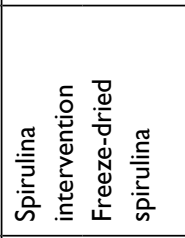 & 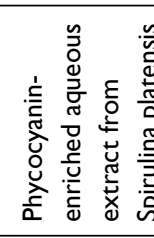 & 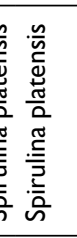 & 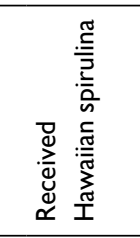 & 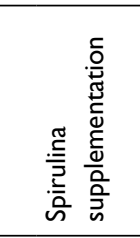 & 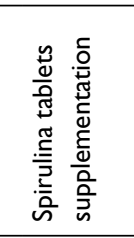 & 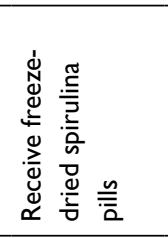 & 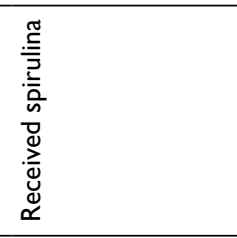 & 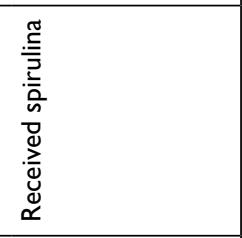 \\
\hline 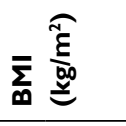 & 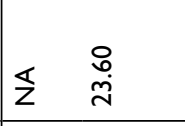 & $\begin{array}{l}0 \\
\text { ஸे } \\
\end{array}$ & $\underset{\stackrel{n}{+}}{\stackrel{\sim}{\sim}}$ & $\begin{array}{l}\text { oे } \\
\text { in }\end{array}$ & 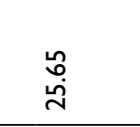 & $\stackrel{\underline{n}}{\stackrel{n}{n}}$ & $\stackrel{\stackrel{n}{m}}{\stackrel{\sim}{\sim}}$ & $\Sigma$ & $\overleftarrow{z}$ \\
\hline ฮ & 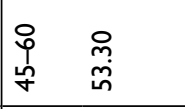 & 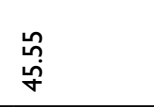 & 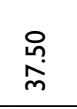 & 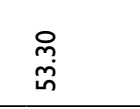 & $\underset{\substack{N \\
\text { N }}}{N}$ & $\begin{array}{l}\text { ำ } \\
\text { ஸे }\end{array}$ & $\begin{array}{l}\text { 응 } \\
\text { Hิ }\end{array}$ & $\begin{array}{l}0 \\
1 \\
o\end{array}$ & $\begin{array}{l}0 \\
0 \\
b\end{array}$ \\
\hline 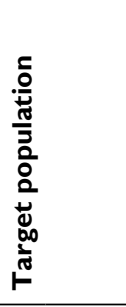 & 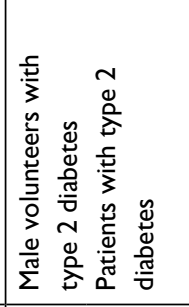 & 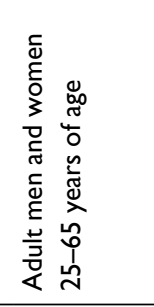 & 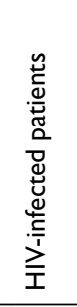 & 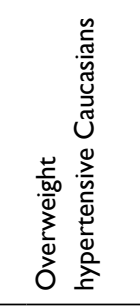 & 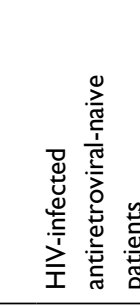 & 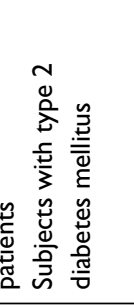 & 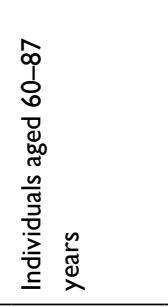 & 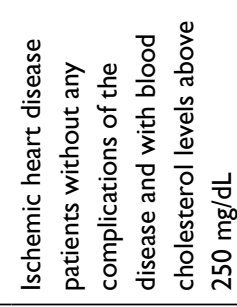 & 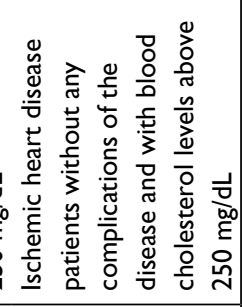 \\
\hline $\begin{array}{l}\frac{0}{0} \\
\frac{\tilde{E}}{n} \\
\text { ñ }\end{array}$ & $\infty \quad \hat{m}$ & $\grave{\lambda}$ & $\tilde{m}$ & 우 & 음 & $\stackrel{\sim}{\sim}$ & $\stackrel{\infty}{\wedge}$ & 요 & 요 \\
\hline בَّ & 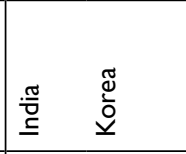 & 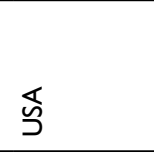 & 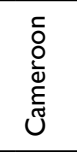 & $\begin{array}{l}\frac{0}{2} \\
\frac{\pi}{0} \\
0\end{array}$ & 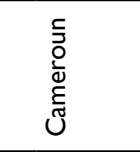 & 吾 & $\begin{array}{l}\tilde{\Xi} \\
\stackrel{0}{0} \\
\end{array}$ & $\underline{\underline{\underline{m}}}$ & $\underline{\underline{\underline{\sigma}}}$ \\
\hline 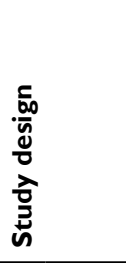 & 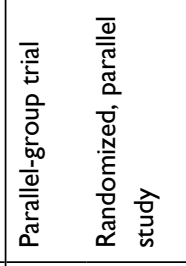 & 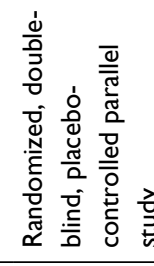 & 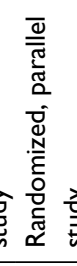 & 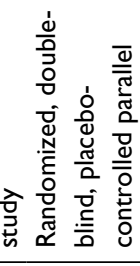 & 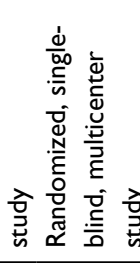 & 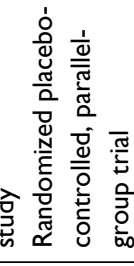 & 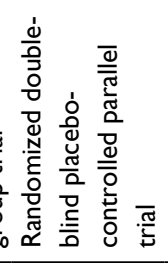 & 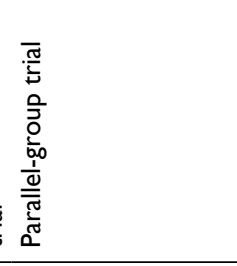 & 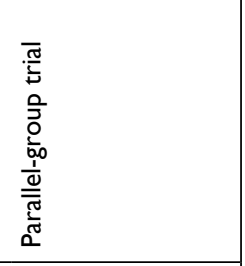 \\
\hline ֻั๊ & 음 & 움 & $\overline{\bar{N}}$ & $\frac{0}{2}$ & $\frac{\pi}{2}$ & চ্ণ & 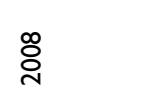 & $\stackrel{\circ}{\sigma}$ & よ̊ \\
\hline 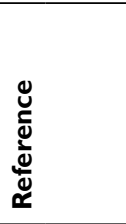 & 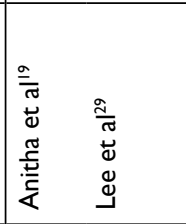 & 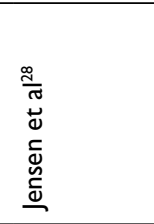 & 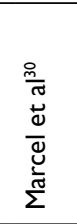 & 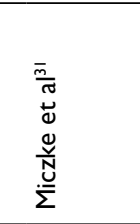 & 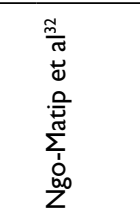 & 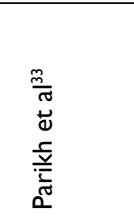 & $\begin{array}{l}\frac{0}{\pi} \\
\frac{0}{0} \\
\frac{0}{\pi} \\
\frac{0}{0}\end{array}$ & 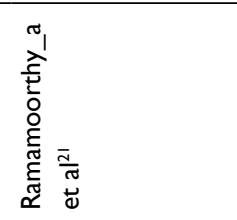 & 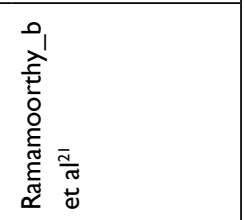 \\
\hline
\end{tabular}




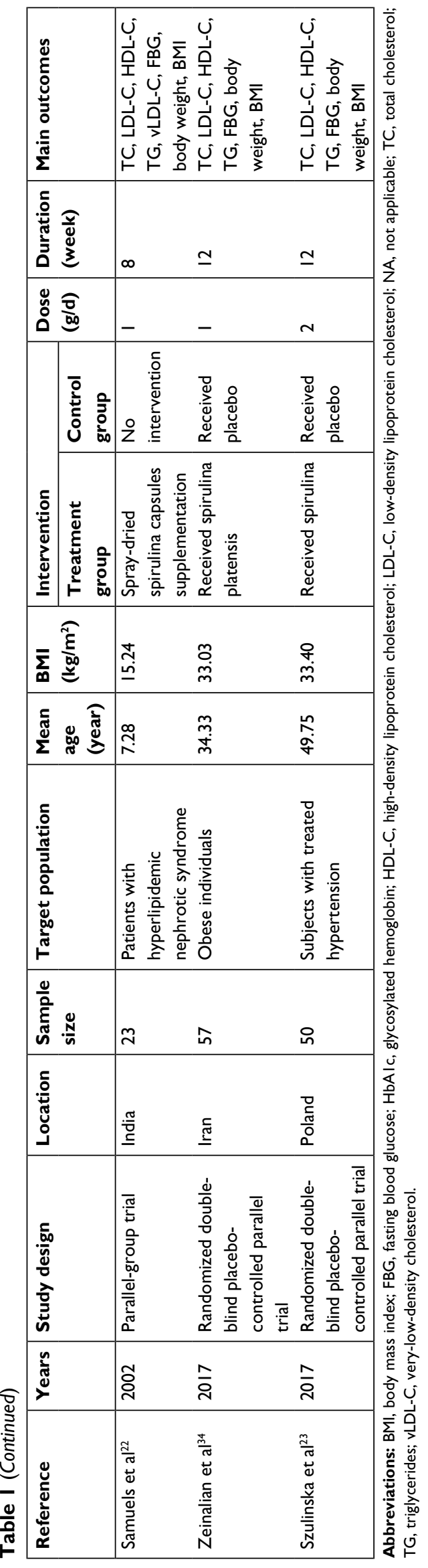

$P=0.0001), \mathrm{LDL}-\mathrm{C}(\mathrm{WMD}=-35.06 \mathrm{mg} / \mathrm{dL} ; 95 \% \mathrm{CI}:-54.30$ to $-15.82 ; P=0.0004)$, and TG (WMD $=-40.65 \mathrm{mg} / \mathrm{dL} ; 95 \%$ CI: -55.82 to $-25.49 ; P=0.0001)$ and increased HDL-C $(\mathrm{WMD}=6.66 \mathrm{mg} / \mathrm{dL} ; 95 \% \mathrm{CI}: 0.22$ to $13.11 ; P=0.04) . \mathrm{In}$ the subgroup analysis by types of control used, the pooled result showed that spirulina supplementation significantly decreased TC $(\mathrm{WMD}=-58.90 \mathrm{mg} / \mathrm{dL} ; 95 \% \mathrm{CI}:-82.53$ to $-35.28 ; P=0.0001)$, LDL-C (WMD $=-54.38 \mathrm{mg} / \mathrm{dL} ; 95 \%$ CI: -80.57 to $-28.19 ; P=0.0001)$, and TG (WMD $=-54.58$ $\mathrm{mg} / \mathrm{dL} ; 95 \% \mathrm{CI}:-70.22$ to $-38.94 ; P=0.0001)$ and increased HDL-C (WMD = $10.46 \mathrm{mg} / \mathrm{dL} ; 95 \%$ CI: 1.73 to 19.19 ; $P=0.02$ ) in trials used no intervention as controls. Significant differences were found on TC concentrations in trials that used placebo as controls (WMD $=-12.74 \mathrm{mg} / \mathrm{dL} ; 95 \% \mathrm{CI}$ : -21.89 to $-3.59 ; P=0.006)$. Complete subgroup results of lipid changes are shown in Table 3.

\section{Sensitivity analysis}

We conducted a sensitivity analysis to further confirm the robustness of the results. The pooled effects of spirulina on lipid profile did not change after systematically dropping each trial (Figure S2). Furthermore, we also omitted the studies that use soybean as a control. The aggregated results were also similar to the overall analysis (Table 3 ).

\section{Adverse events}

Among these trials, spirulina were well-tolerated. The adverse event rate was similar in the experimental and control groups, and no serious adverse events occurred among most of the eligible trials during the follow-up period.

\section{Publication bias}

No obvious publication bias was discerned in the visual inspection of funnel plots (Figure S3). Similarly, Begg's rank correlation and Egger's linear regression tests were also performed to confirm the publication bias. The results of Begg's test and Egger's test were listed in Table 4. These results did not show any evidence of publication bias in the present analysis (all $P>0.05$ ). We did not perform publication bias test for HbAlc, SBP, and DBP due to lack of sufficient studies $(\mathrm{n}<5)$.

\section{Discussion}

CVD is the leading cause of death worldwide, accounting for about one in three deaths. To reduce the incidence of CVD, targeting metabolic risk factors by nontoxic antioxidant nutrient supplement or functional food with cardiovascular protective properties is of great importance. Their mechanism 


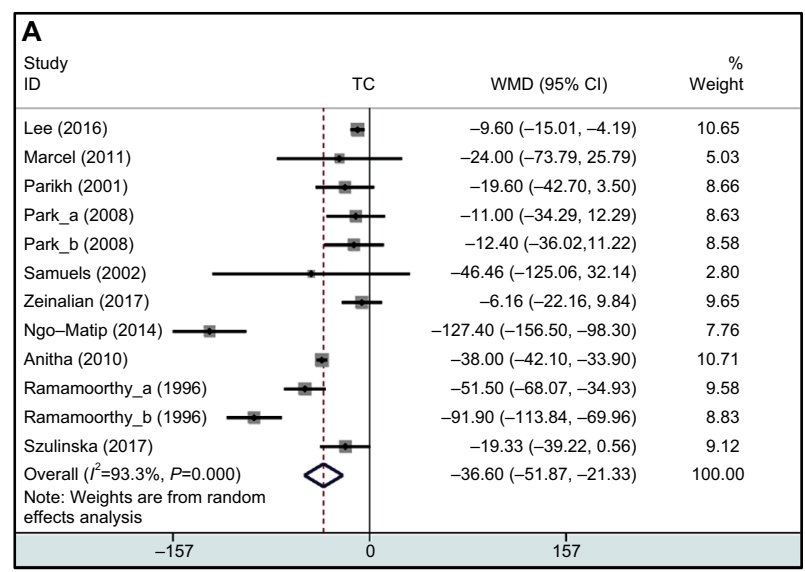

\begin{tabular}{|c|c|c|c|}
\hline $\begin{array}{l}\text { B } \\
\text { Study } \\
\text { ID }\end{array}$ & LDL-C & WMD $(95 \% \mathrm{Cl})$ & $\begin{array}{l}\% \\
\text { Weight }\end{array}$ \\
\hline Lee (2016) & & $-3.30(-7.58,0.98)$ & 10.65 \\
\hline Parikh (2001) & & $-16.50(-36.06,3.06)$ & 9.44 \\
\hline Park_a (2008) & & $-2.50(-27.01,22.01)$ & 8.83 \\
\hline Park_b (2008) & & $-10.10(-36.17,15.97)$ & 8.63 \\
\hline Samuels (2002) & & $-33.01(-92.22,26.20)$ & 4.77 \\
\hline Zeinalian (2017) & & $2.48(-11.76,16.72)$ & 10.00 \\
\hline Ngo-Matip (2014) $\longleftarrow$ & & $-123.88(-152.25,-95.51)$ & 8.33 \\
\hline Anitha (2010) & & $-39.00(-43.73,-34.27)$ & 10.63 \\
\hline Ramamoorthy_a (1996) & & $-46.10(-62.07,-30.13)$ & 9.83 \\
\hline Ramamoorthy_b (1996) $\longrightarrow$ & & $-85.80(-106.59,-65.01)$ & 929 \\
\hline Szulinska (2017) & & $-19.33(-37.48,-1.18)$ & 9.59 \\
\hline Overall $\left(I^{2}=95.7 \%, P=0.000\right)$ & & $-33.16(-50.52,-15.79)$ & 100.00 \\
\hline \multicolumn{4}{|l|}{$\begin{array}{l}\text { Note: Weights are from random } \\
\text { effects analysis }\end{array}$} \\
\hline-152 & 0 & 15 & \\
\hline
\end{tabular}

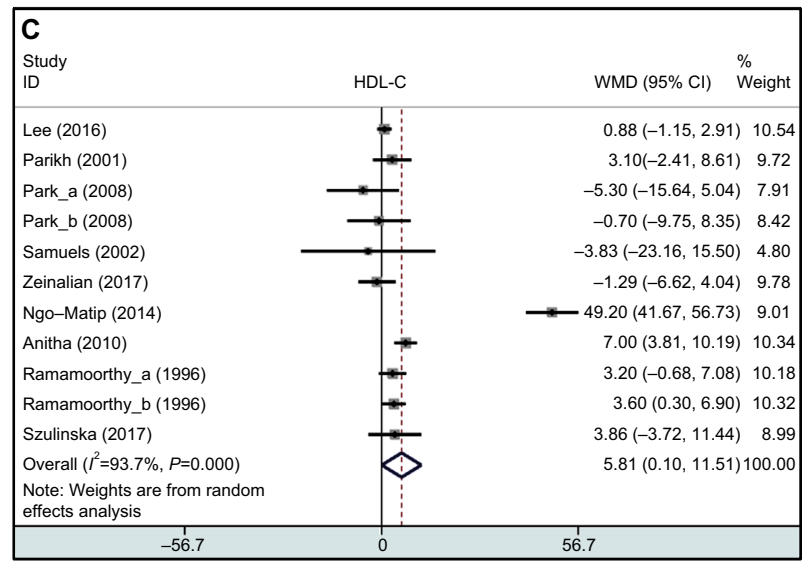

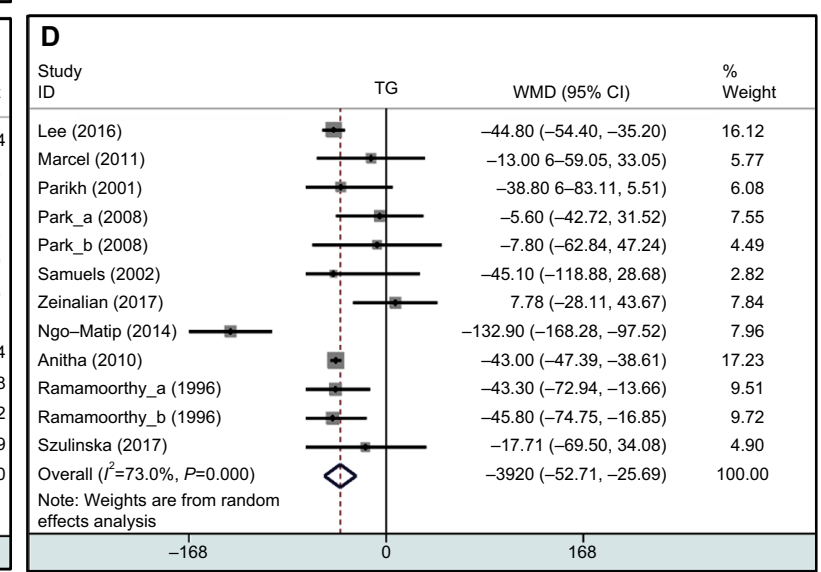

Figure 2 Forest plot detailing weighted mean difference and $95 \%$ Cls for the effects of spirulina supplementation on TC (A), LDL-C (B), HDL-C (C), and TG (D) in humans. Abbreviations: HDL-C, high-density lipoprotein cholesterol; LDL-C, low-density lipoprotein cholesterol; TG, triglycerides; TC, total cholesterol; WMD, weighted mean differences.

Table 2 Effect of spirulina consumption on other markers of cardiovascular disease

\begin{tabular}{|c|c|c|c|c|c|}
\hline Markers outcomes & No. of treatment arms & No. of patients & WMD $(95 \% \mathrm{Cl})$ & $P$-value & $I^{2}, \%$ \\
\hline vLDL-C (mg/dL) & 5 & 167 & $-8.02(-8.77$ to -7.26$)$ & $0.000 I^{*}$ & 0 \\
\hline FBG (mg/dL) & 8 & 411 & $-5.01(-9.78$ to -0.24$)$ & $0.04 *$ & 51 \\
\hline $\mathrm{HbAlc}$ & 3 & 82 & $-0.34(-0.79$ to 0.11$)$ & 0.14 & 78 \\
\hline $\mathrm{SBP}(\mathrm{mmHg})$ & 4 & $|4|$ & $-3.49(-7.19$ to 0.21$)$ & 0.06 & 50 \\
\hline $\mathrm{DBP}(\mathrm{mmHg})$ & 4 & $|4|$ & $-7.17(-8.57$ to -5.78$)$ & $0.000 I^{*}$ & 0 \\
\hline Body weight (kg) & 7 & 276 & $-1.51(-3.39$ to 0.36$)$ & 0.11 & 0 \\
\hline BMI $\left(\mathrm{kg} / \mathrm{m}^{2}\right)$ & 5 & 354 & $-0.44(-1.87$ to 0.99$)$ & 0.54 & 71 \\
\hline
\end{tabular}

Notes: *Indicates a significant result.

Abbreviations: BMI, body mass index; FBG, fasting blood glucose; HbAlc, glycosylated hemoglobin; vLDL-C, very-low-density cholesterol; WMD, weighted mean differences.

of action is based primarily on reducing oxidative stress, enhancing NO synthesis, reducing LDL oxidation, inhibiting the growth of smooth muscle cells of blood vessels, modulating insulin resistance, and reducing BP. In the current meta-analysis, we focused on the evidence regarding the efficacy and safety of spirulina supplementation on the major CVD risk markers, including lipid parameters, BP, body weight, and glucose. Results from our pooled analysis of 12 identified studies with 14 treatment arms demonstrate that patients receiving spirulina had statistically significant lower
TC, LDL-C, TG, vLDL-C, FBG, and DBP after treatment than did control patients. However, the use of spirulina did not substantially affect HDL-C, SBP, HbAlc, body weight, and BMI values compared with those in the control group. These changes varied substantially depending on the types of controls used, spirulina dose, and intervention duration. In our subgroup analysis, the lipid-modifying effects of spirulina were also found in subjects that ingested a dose of spirulina $>2 \mathrm{~g} / \mathrm{d}$ and subjects with spirulina intervention $\geq 12$ weeks. The pooled result was robust and remained significant in the 


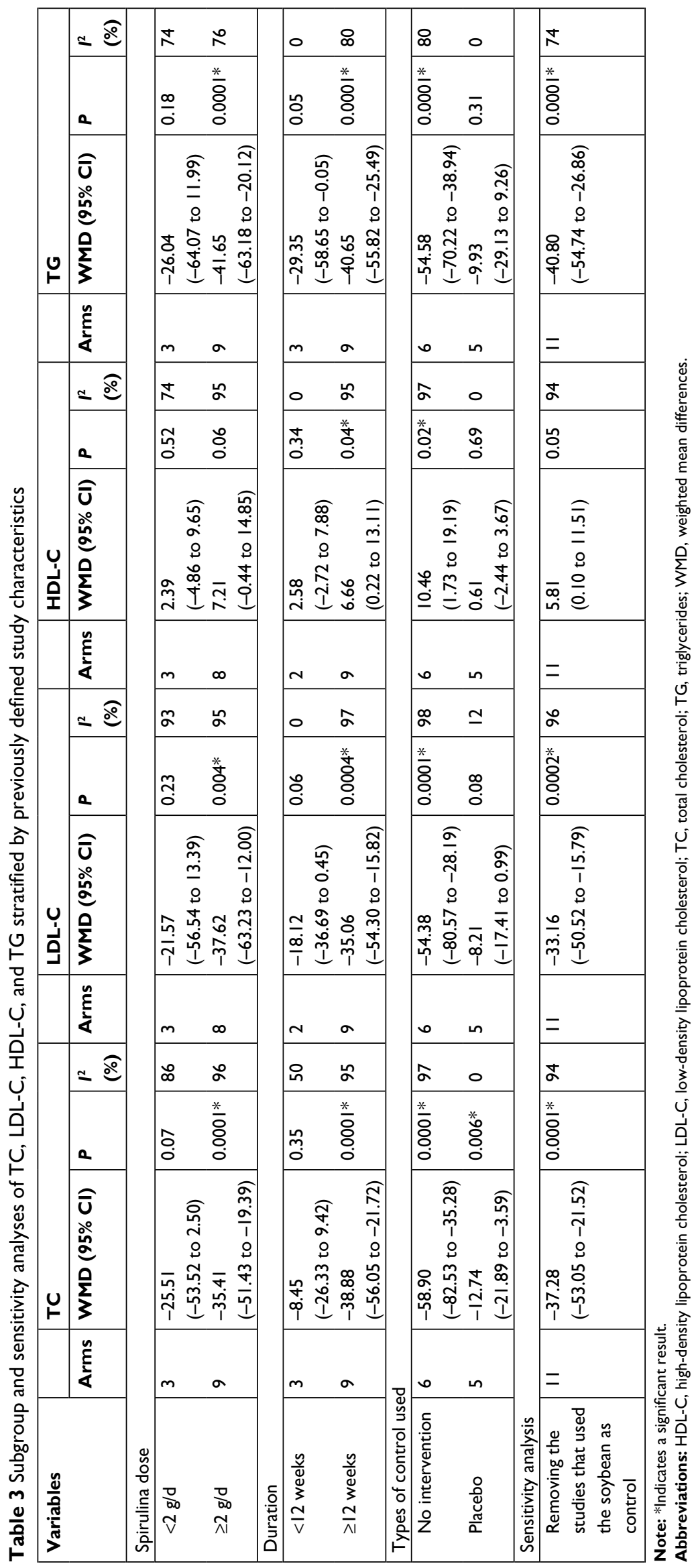


Table 4 Publication bias in the meta-analysis of studies

\begin{tabular}{|c|c|c|c|c|c|c|}
\hline \multirow[t]{2}{*}{ Outcomes } & \multicolumn{2}{|c|}{ Begg's rank correlation test } & \multicolumn{4}{|c|}{ Egger's linear regression test } \\
\hline & $Z$ value & $P$-value & Intercept $(95 \% \mathrm{Cl})$ & $t$ & $d f$ & $P$-value \\
\hline TC & 0.75 & 0.451 & -0.85 ( -4.58 to 2.88$)$ & $-0.5 \mathrm{I}$ & 11 & 0.622 \\
\hline LDL-C & 0.62 & 0.533 & $-1.94(-6.96$ to 3.08$)$ & -0.87 & 10 & 0.405 \\
\hline HDL-C & 0.16 & 0.876 & $1.78(-3.70$ to 7.25$)$ & 0.73 & 10 & $0.48 I$ \\
\hline TG & 1.17 & 0.244 & $0.37(-1.29$ to 2.03$)$ & 0.50 & 11 & 0.628 \\
\hline vLDL-C & 1.22 & 0.221 & $0.19(-0.87$ to 1.25$)$ & 0.57 & 4 & 0.610 \\
\hline FBG & 2.10 & 0.035 & $-1.45(-3.46$ to 0.56$)$ & -1.76 & 7 & 0.129 \\
\hline Body weight & 1.36 & 0.174 & $-0.97(-3.13$ to 1.20$)$ & -1.09 & 7 & 0.316 \\
\hline BMI & 0.19 & 0.851 & $0.40(-6.9 \mid$ to $7.7 I)$ & 0.15 & 5 & 0.886 \\
\hline
\end{tabular}

Abbreviations: BMI, body mass index; df, degrees of freedom; FBG, fasting blood glucose; HDL-C, high-density lipoprotein cholesterol; LDL-C, low-density lipoprotein cholesterol; TC, total cholesterol; TG, triglycerides; vLDL-C, very-low-density cholesterol.

leave-one-out sensitivity analysis. Spirulina consumption might be utilized as nutraceuticals or functional foods for the prevention and treatment of CVD in humans.

The results of our meta-analysis are remarkably similar to the study performed by Serban et $\mathrm{al}^{35}$ regarding $\mathrm{TC}$, LDL-C, and TG, but in contrast to HDL-C. Previous study included seven trials with 522 participants for analysis and indicated that spirulina supplementation significantly lowered TC $(P<0.001)$, LDL-C $(P<0.001)$, and TG $(P=0.001)$ and elevated those of HDL-C $(P<0.001) .{ }^{35}$ For our present analysis, we included other five recent double-blind, placebocontrolled, randomized clinical trials, giving greater power to evaluate these beneficial effect. Furthermore, other identified CVD risk markers, such as body weight, BMI, FBG, HbA1c, SBP, and DBP, were also systematically evaluated in our present analysis following spirulina consumptions, which had not been assessed in previous reviews. Our present analysis is the latest and the most comprehensive one and will provide clinicians with an unbiased consensus of the current human clinical trial data, which can be directly applied to practice while also highlighting directions for future clinical research.

Dyslipidemia, hypertension, and insulin resistance promote endothelial dysfunction and vascular inflammation leading to atherosclerosis. ${ }^{36}$ There is sufficient evidence showing that interventions with lipid-lowering therapies have the potential role in reducing the risk of atherosclerotic CVD. ${ }^{37,38}$ Antioxidants now play a significant role in preventing the accumulation of lipids in blood vessels by eliminating the lipid peroxides derived through lipid peroxidation and free radicals. ${ }^{39}$ According to the clinical practice guidelines, LDL-C is considered to be the main target for lipid-lowering treatment, with a $1 \%$ reduction associated with a $1 \%$ decrease in CVD events. ${ }^{40}$ The lipid-modifying effects of spirulina were established in our present meta-analysis, especially on TC, LDL-C, and TG. However, the precise mechanisms responsible for the presumed lipid-lowering properties of spirulina are not fully explored. It has been shown that the hypocholesterolemic action of spirulina platensis concentrate may involve the inhibition of both jejunal cholesterol absorption and ileal bile acid reabsorption, as well as increase fecal cholesterol and bile acid excretion. ${ }^{41,42}$ Moreover, the decrease in the lipid level can be also attributed to the spirulina antioxidant metabolites characteristic. C-phycocyanin, the main ingredient of spirulina, reduces the lipid concentrations through scavenging free radicals, inhibiting lipid peroxidation, nicotinamide adenine dinucleotide phosphate oxidase expression, and increasing the activity of lipoprotein lipase, hepatic triglyceride lipase, glycosylated serum protein peroxidase and superoxide dismutase. ${ }^{43-45}$ The effects of spirulina administration on atherosclerosis are also revealed by in vivo study, in which spirulina has been shown to activate the atheroprotective heme oxygenase- 1 in endothelial cells. ${ }^{46}$

Hypertension, hyperglycemia, and high level of HbAlc are regarded as key risk factors for the development of atherosclerotic CVD in humans. ${ }^{47}$ Therefore, assessment of glycemic and BP control is also a crucial element of effective primary and secondary CVD prevention. FBG levels are generally used to evaluate the efficacy of dietary supplements and glycemic-lowering drugs. Our pooled result revealed that FBG and DBP levels were significantly reduced following spirulina interventions. However, no significant change was found in $\mathrm{HbAl}$. Persistence of excess adiposity is associated with the progression of metabolic abnormality, whereas the control of weight gain may relieve the risk of these metabolicrelated complications. Greater weight loss generates greater benefit in terms of meaningful reductions in serum lipids, BP, blood glucose, and the risk of developing metabolism syndrome. ${ }^{48}$ However, we failed to find any statistically significant differences in body weight between the spirulina 
products and the control groups. It should be noted that these results are inconclusive because the number of eligible clinical trial was relatively small; further, large-scale randomized controlled trials are required to confirm the present results.

Our findings may have major implications for clinical practice and further research, given that the metabolic biomarkers evaluated in our present study are clinically relevant for evaluating treatment and progression of CVD. However, our present meta-analysis is not without weaknesses. First, although extensive searches with clear inclusion criteria were formulated, we may not have entirely identified all relevant articles involving the use of spirulina especially unpublished trials and gray literature. Second, although no significant publication bias was detected in our study, we observed a high degree of heterogeneity between studies that was not completely resolved by numerous subgroup and sensitivity analyses. The sources of the heterogeneity are most probably ascribed by the differences in study design, target populations (ie, subjects with type 2 diabetes mellitus, HIV-infected, hypertension, ischemic heart disease, and hyperlipidemic nephrotic syndrome), and characteristics (ie, age, sex, and baseline BMI). Third, there were variations in reporting quality of included studies. Most of the trials were characterized by insufficient information about the sequence generation, allocation concealment, and types of blinding. These factors may have a potential impact on the precision of the effect sizes. Finally, due to the lack of information in most of the existing studies, some other confounding factors were unable to be taken into consideration, such as physical activities and other dietary factors intervention.

\section{Summary and conclusion}

In summary, based on the currently available literature, our meta-analysis revealed a significant benefit of spirulina supplementation in improving multiple markers of cardiovascular health including TC, LDL-C, TG, vLDL-C, FBG, and DBP, without any significant side-effects. The pooled results indicate clinically important improvements in CVD risk profile. Spirulina consumption may be considered as an adjunct to the prevention and treatment of CVD in humans. Further larger high-quality, double-blind, randomized clinical trials investigating the long-term effects and risk of spirulina supplementation on cardiovascular metabolic biomarkers and cardiovascular morbidity are needed.

\section{Abbreviations}

BMI, body mass index; CVD, cardiovascular disease; FBG, fasting blood glucose; HbA1c, glycosylated hemoglobin; HDL-C, high-density lipoprotein cholesterol; LDL-C, low-density lipoprotein cholesterol; TC, total cholesterol; TG, triglycerides; vLDL-C, very-low-density cholesterol; WMDs, weighted mean differences.

\section{Acknowledgment}

This work was supported by the Traditional Medicine Research Program of Guangdong Province (No. 20181270).

\section{Author contributions}

$\mathrm{HH}$ contributed to conception and design of the study, acquisition of data, analysis and interpretation of data, drafted the manuscript, discussed the idea of the meta-analysis, and submitted the paper; DL and RP completed the database searches and selected, reviewed the articles, and extracted the data; YC contributed to conception and design of the study, reviewed and extracted the data, and performed the data analyses. All authors contributed to data analysis, drafting or revising the article, gave final approval of the version to be published, and agree to be accountable for all aspects of the work.

\section{Disclosure}

The authors report no conflicts of interest in this work.

\section{References}

1. Smith SC, Collins A, Ferrari R, et al. Our time: a call to save preventable death from cardiovascular disease (heart disease and stroke). Circulation. 2012;126(23):2769-2775.

2. Yusuf S, Hawken S, Ounpuu S, et al. Effect of potentially modifiable risk factors associated with myocardial infarction in 52 countries (the INTERHEART study): case-control study. Lancet. 2004;364(9438):937-952.

3. Banach M, Aronow WS. Hypertension therapy in the older adults-do we know the answers to all the questions? The status after publication of the ACCF/AHA 2011 expert consensus document on hypertension in the elderly. $J$ Hum Hypertens. 2012;26(11):641-643.

4. Writing Group Members, Lloyd-Jones D, Adams RJ, et al. Heart disease and stroke statistics--2010 update: a report from the American Heart Association. Circulation. 2010;121(7):e46-e215.

5. Mozaffarian D, Benjamin EJ, Go AS, et al. Heart disease and stroke statistics--2015 update: a report from the American Heart Association. Circulation. 2015;131(4):e29-322.

6. Lewington S, Clarke R, Qizilbash N, Peto R, Collins R, Prospective Studies Collaboration. Age-specific relevance of usual blood pressure to vascular mortality: a meta-analysis of individual data for one million adults in 61 prospective studies. Lancet. 2002;360(9349): 1903-1913.

7. Grundy SM, Cleeman JI, Daniels SR, et al. Diagnosis and management of the metabolic syndrome: an American Heart Association/National Heart, Lung, and Blood Institute scientific statement. Curr Opin Cardiol. 2006;21(1):1-6.

8. Huang H, Chen G, Liao D, Zhu Y, Xue X. Effects of berries consumption on cardiovascular risk factors: a meta-analysis with trial sequential analysis of randomized controlled trials. Sci Rep. 2016;6:23625.

9. Huang H, Zou Y, Chi H, Liao D. Lipid-modifying effects of chitosan supplementation in humans: a pooled analysis with trial sequential analysis. Mol Nutr Food Res. 2018;62(8):e1700842:1700842. 
10. Huang H, Chen G, Liao D, Zhu Y, Pu R, Xue X. The effects of resveratrol intervention on risk markers of cardiovascular health in overweight and obese subjects: a pooled analysis of randomized controlled trials. Obes Rev. 2016;17(12):1329-1340.

11. Stepien M, Kujawska-Luczak M, Szulinska M, et al. Beneficial doseindependent influence of Camellia sinensis supplementation on lipid profile, glycemia, and insulin resistance in an $\mathrm{NaCl}$-induced hypertensive rat model. J Physiol Pharmacol. 2018;69(2).

12. Szulińska M, Stępień M, Kręgielska-Narożna M, et al. Effects of green tea supplementation on inflammation markers, antioxidant status and blood pressure in NaCl-induced hypertensive rat model. Food Nutr Res. 2017;61(1):1295525.

13. Mazokopakis EE, Karefilakis CM, Tsartsalis AN, Milkas AN, Ganotakis ES. Acute rhabdomyolysis caused by Spirulina (Arthrospira platensis) Phytomedicine. 2008;15(6-7):525-527.

14. Khan Z, Bhadouria P, Bisen PS. Nutritional and therapeutic potential of Spirulina. Curr Pharm Biotechnol. 2005;6(5):373-379.

15. Deng R, Chow TJ. Hypolipidemic, antioxidant, and antiinflammatory activities of microalgae Spirulina. Cardiovasc Ther. 2010;28(4):e33-e45.

16. Martínez-Galero E, Pérez-Pastén R, Perez-Juarez A, Fabila-Castillo L, Gutiérrez-Salmeán G, Chamorro G. Preclinical antitoxic properties of Spirulina (Arthrospira). Pharm Biol. 2016;54(8):1345-1353.

17. Gutiérrez-Salmeán G, Fabila-Castillo L, Chamorro-Cevallos G. Nutritional and toxicological aspects of Spirulina (Arthrospira). Nutr Hosp. 2015;32(1):34-40.

18. Karkos PD, Leong SC, Karkos CD, Sivaji N, Assimakopoulos DA. Spirulina in clinical practice: evidence-based human applications. Evid Based Complement Alternat Med. 2011;2011:1-4.

19. Anitha L, Chandralekha K. Effect of supplementation of spirulina on blood glucose, glycosylated hemoglobin and lipid profile of male non-insulin dependent diabetics. Asian J Exp Biol Sci. 2010;1(1): 36-46.

20. Park HJ, Lee YJ, Ryu HK, Kim MH, Chung HW, Kim WY. A randomized double-blind, placebo-controlled study to establish the effects of spirulina in elderly Koreans. Ann Nutr Metab. 2008;52(4):322-328.

21. Ramamoorthy A, Premakumari S. Effect of supplementation of Spirulina on hypercholesterolemic patients. J Food Sci Technol. 1996;33(2):124-128.

22. Samuels R, Mani UV, Iyer UM, Nayak US. Hypocholesterolemic effect of spirulina in patients with hyperlipidemic nephrotic syndrome. J Med Food. 2002;5(2):91-96.

23. Szulinska M, Gibas-Dorna M, Miller-Kasprzak E, et al. Spirulina maxima improves insulin sensitivity, lipid profile, and total antioxidant status in obese patients with well-treated hypertension: a randomized double-blind placebo-controlled study. Eur Rev Med Pharmacol Sci. 2017;21(10):2473-2481.

24. Liberati A, Altman DG, Tetzlaff J. The PRISMA statement for reporting systematic reviews and meta-analyses of studies that evaluate health care interventions: explanation and elaboration. Ann Intern Med. 2009; 151(4):W-94.

25. Higgins JP, Green S. Cochrane Handbook for System-atic Reviews of Interventions Version 5.1.0. (updated March 2011). Available from http://handbook.cochrane.org/. Accessed October 25, 2018.

26. Higgins JP, Thompson SG, Deeks JJ, Altman DG. Measuring inconsistency in meta-analyses. BMJ. 2003;327(7414):557-560.

27. Egger M, Davey Smith G, Schneider M, Minder C. Bias in meta-analysis detected by a simple, graphical test. BMJ. 1997;315(7109):629-634.

28. Jensen GS, Drapeau C, Lenninger M, Benson KF. Clinical safety of a high dose of phycocyanin-enriched aqueous extract from Arthrospira (Spirulina) platensis: results from a randomized, double-blind, placebocontrolled study with a focus on anticoagulant activity and platelet activation. J Med Food. 2016;19(7):645-653.
29. Lee EH, Park JE, Choi YJ, Huh KB, Kim WY. A randomized study to establish the effects of spirulina in type 2 diabetes mellitus patients. Nutr Res Pract. 2008;2(4):295-300.

30. Marcel AK, Ekali LG, Eugene S, et al. The effect of Spirulina platensis versus soybean on insulin resistance in HIV-infected patients: a randomized pilot study. Nutrients. 2011;3(7):712-724.

31. Miczke A, Szulińska M, Hansdorfer-Korzon R, et al. Effects of spirulina consumption on body weight, blood pressure, and endothelial function in overweight hypertensive Caucasians: a double-blind, placebo-controlled, randomized trial. Eur Rev Med Pharmacol Sci. 2016;20(1):150-156.

32. Ngo-Matip ME, Pieme CA, Azabji-Kenfack M, et al. Effects of Spirulina platensis supplementation on lipid profile in HIV-infected antiretroviral naïve patients in Yaounde-Cameroon: a randomized trial study. Lipids Health Dis. 2014;13:191.

33. Parikh P, Mani U, Iyer U. Role of spirulina in the control of glycemia and lipidemia in type 2 diabetes mellitus. J Med Food. 2001;4(4):193-199.

34. Zeinalian R, Farhangi MA, Shariat A, Saghafi-Asl M. The effects of Spirulina Platensis on anthropometric indices, appetite, lipid profile and serum vascular endothelial growth factor (VEGF) in obese individuals: a randomized double blinded placebo controlled trial. BMC Complement Altern Med. 2017;17(1):225.

35. Serban MC, Sahebkar A, Dragan S, et al. A systematic review and meta-analysis of the impact of Spirulina supplementation on plasma lipid concentrations. Clin Nutr. 2016;35(4):842-851.

36. Srikanth S, Deedwania P. Management of dyslipidemia in patients with hypertension, diabetes, and metabolic syndrome. Curr Hypertens Rep. 2016;18(10):76.

37. Barter PJ, Rye KA. New era of lipid-lowering drugs. Pharmacol Rev. 2016;68(2):458-475.

38. Baigent C, Keech A, Kearney PM, et al. Efficacy and safety of cholesterol-lowering treatment: prospective meta-analysis of data from 90,056 participants in 14 randomised trials of statins. Lancet. 2005;366(9493):1267-1278.

39. Kata FS, Athbi AM, Manwar EQ, Al-Ashoor A, Abdel-Daim MM, Aleya L. Therapeutic effect of the alkaloid extract of the cyanobacterium Spirulina platensis on the lipid profile of hypercholesterolemic male rabbits. Environ Sci Pollut Res Int. 2018:19635-19642.

40. Russell C, Sheth S, Jacoby D. A clinical guide to combination lipidlowering therapy. Curr Atheroscler Rep. 2018;20(4):19.

41. Nagaoka S, Shimizu K, Kaneko H, et al. A novel protein C-phycocyanin plays a crucial role in the hypocholesterolemic action of Spirulina platensis concentrate in rats. J Nutr. 2005;135(10):2425-2430.

42. Kulshreshtha A, Zacharia AJ, Jarouliya U, Bhadauriya P, Prasad GB, Bisen PS. Spirulina in health care management. Curr Pharm Biotechnol. 2008;9(5):400-405.

43. Upasani CD, Balaraman R. Protective effect of Spirulina on lead induced deleterious changes in the lipid peroxidation and endogenous antioxidants in rats. Phytother Res. 2003;17(4):330-334.

44. Han LK, Li DX, Xiang L, et al. Isolation of pancreatic lipase activityinhibitory component of spirulina platensis and it reduce postprandial triacylglycerolemia. Yakugaku Zasshi. 2006;126(1):43-49.

45. Ku CS, Yang Y, Park Y, Lee J. Health benefits of blue-green algae: prevention of cardiovascular disease and nonalcoholic fatty liver disease. J Med Food. 2013;16(2):103-111.

46. Strasky Z, Zemankova L, Nemeckova I, et al. Spirulina platensis and phycocyanobilin activate atheroprotective heme oxygenase-1: a possible implication for atherogenesis. Food Funct. 2013;4(11):1586-1594.

47. Retnakaran R, Cull CA, Thorne KI, Adler AI, Holman RR; UKPDS Study Group. Risk factors for renal dysfunction in type 2 diabetes: U.K. Prospective Diabetes Study 74. Diabetes. 2006;55(6):1832-1839.

48. Wenger NK. Prevention of cardiovascular disease: highlights for the clinician of the 2013 American College of Cardiology/American Heart Association guidelines. Clin Cardiol. 2014;37(4):239-251. 


\section{Supplementary materials}

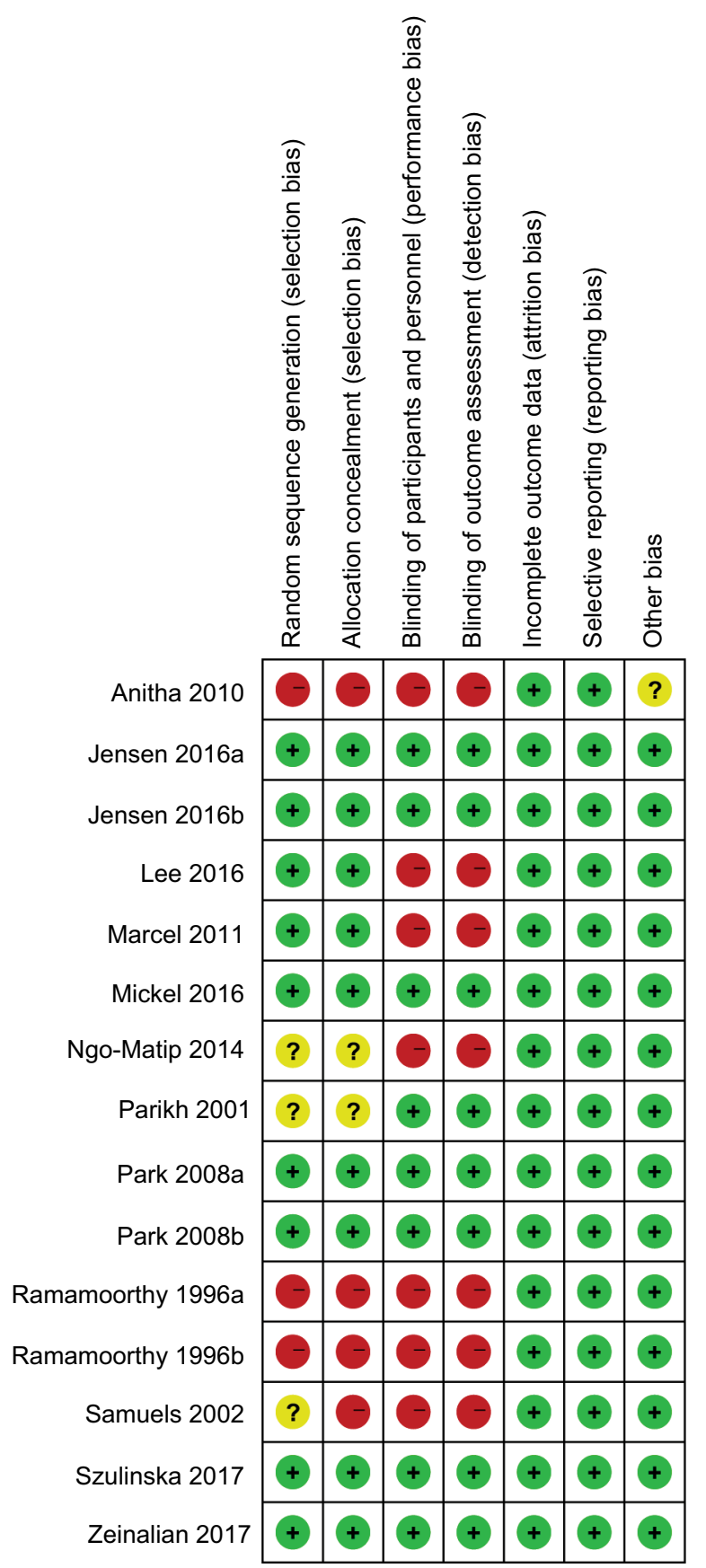

Figure SI Quality assessment of the included studies. Labeling an item as a "question mark" indicated an unclear or unknown risk of bias; Labeling an item as a "negative sign" indicated a high risk of bias; Labeling an item as a "positive sign" indicated a low risk of bias. 

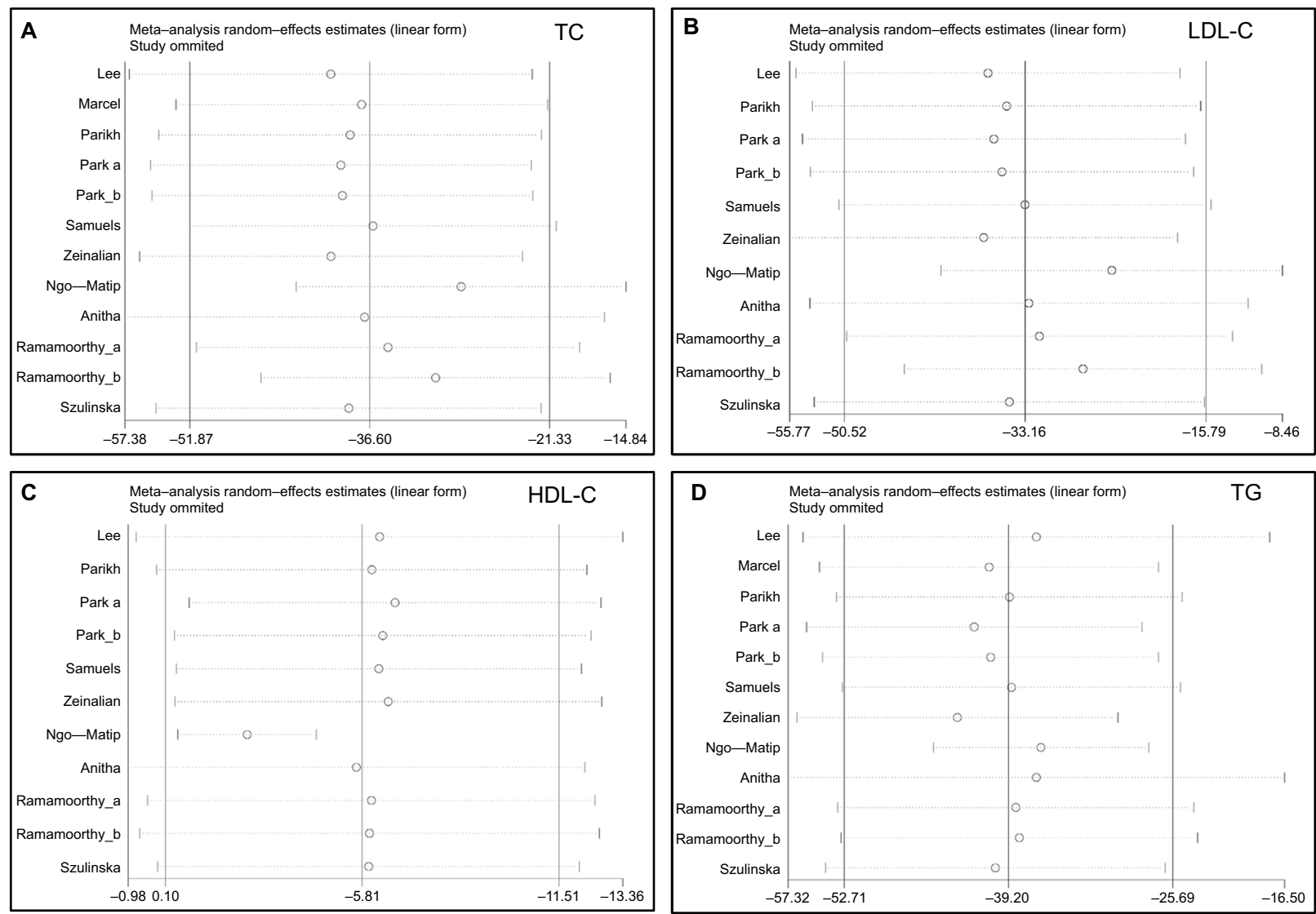

Figure S2 Sensitivity analysis was conducted on outcomes of TC (A), LDL-C (B), HDL-C (C), and TG (D) using the leave-one-out method. Abbreviations: HDL-C, high-density lipoprotein cholesterol; LDL-C, low-density lipoprotein cholesterol; TC, total cholesterol; TG, triglycerides.
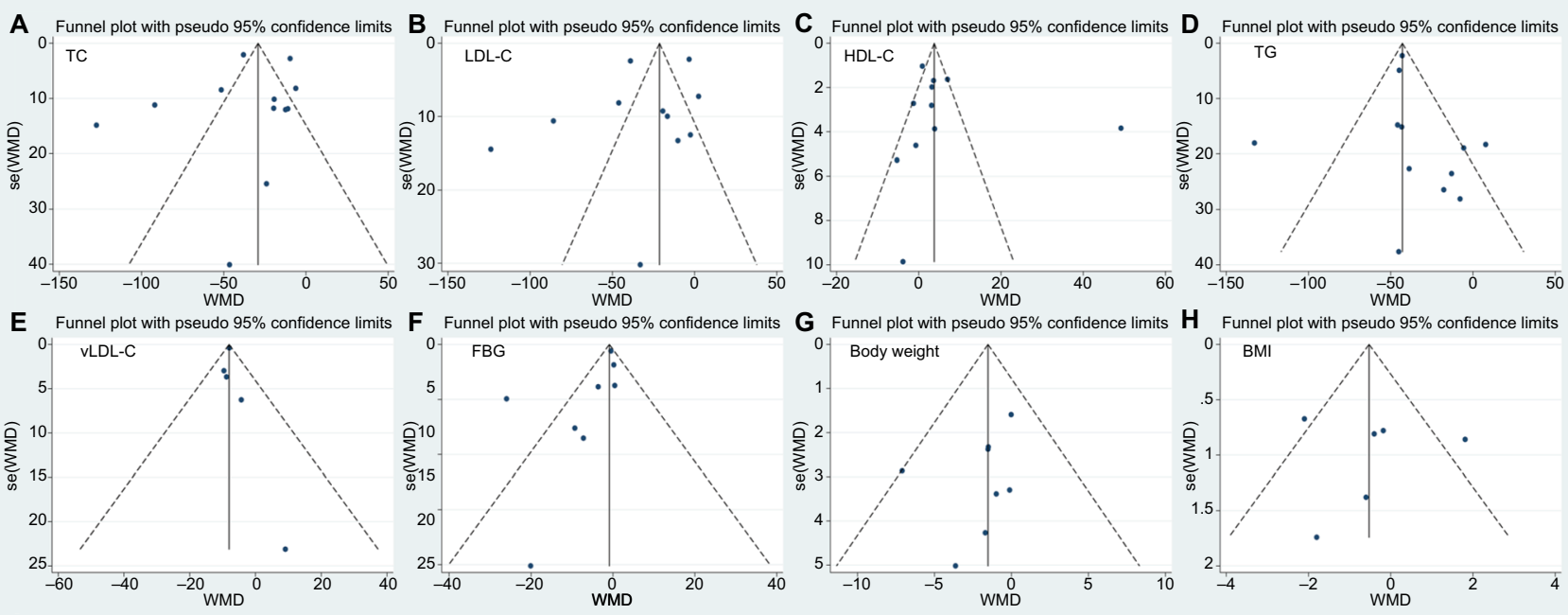

Figure S3 Funnel plots with pseudo 95\% Cls for publication bias of TC (A), LDL-C (B), HDL-C (C), TG (D), vLDL-L (E), FBG (F), body weight (G), and BMI (H). Abbreviations: BMI, body mass index; FBG, fasting blood glucose; HDL-C, high-density lipoprotein cholesterol; LDL-C, low-density lipoprotein cholesterol; TC, total cholesterol; TG, triglycerides; vLDL-C, very-low-density cholesterol. 
Diabetes, Metabolic Syndrome and Obesity: Targets and Therapy is an international, peer-reviewed open-access journal committed to the rapid publication of the latest laboratory and clinical findings in the fields of diabetes, metabolic syndrome and obesity research. Original research, review, case reports, hypothesis formation, expert opinion and commentaries are all considered for publication. The manuscript management system is completely online and includes a very quick and fair peer-review system, which is all easy to use. Visit http://www.dovepress.com/testimonials.php to read real quotes from published authors.

Submit your manuscript here: https://www.dovepress.com/diabetes-metabolic-syndrome-and-obesity-targets-and-therapy-journal 